\title{
The relationship between obesity and neurocognitive function in Chinese patients with schizophrenia
}

\author{
Xiaofeng Guo ${ }^{1}$, Zhanchou Zhang ${ }^{1}$, Qinling Wei ${ }^{2}$, Hailong Lv ${ }^{1}$, Renrong $\mathrm{Wu}^{1}$ and Jingping Zhao ${ }^{1 *}$
}

\begin{abstract}
Background: Studies have reported that up to $60 \%$ of individuals with schizophrenia are overweight or obese. This study explored the relationship between obesity and cognitive performance in Chinese patients with schizophrenia.

Methods: Outpatients with schizophrenia aged 18-50 years were recruited from 10 study sites across China. Demographic and clinical information was collected. A neuropsychological battery including tests of attention, processing speed, learning/memory, and executive functioning was used to assess cognitive function, and these 4 individual domains were transformed into a neurocognitive composite z score. In addition, height and weight were measured to calculate body mass index (BMI). Patients were categorized into 4 groups (underweight, normal weight, overweight and obese) based on BMI cutoff values for Asian populations recommended by the World Health Organization.
\end{abstract}

Results: A total number of 896 patients were enrolled into the study. Fifty-four percent of participants were overweight or obese. A higher BMI was significantly associated with lower scores on the Wechsler Memory Scale-Revised (WMS-R) Visual Reproduction subscale, the Wechsler Adult Intelligence Scale-Revised (WAIS-R) Digit Symbol subscale, and the composite z score (p's $\leq$ 0.024). Obese patients with schizophrenia had significantly lower scores than normal weight patients on the Trail Making Test B, the WMS-R Visual Reproduction subscale, the WAIS Digit Symbol subscale, and the composite z score ( $p^{\prime} s \leq 0.004$ ).

Conclusions: Our study suggests that, in addition to its well established risk for various cardiometabolic conditions, obesity is also associated with decreased cognitive function in Chinese patients with schizophrenia. Future studies should explore if weight loss and management can improve cognitive function in obese patients who suffer from schizophrenia.

Keywords: Schizophrenia, Cognitive function, Body mass index, Obesity, Overweight

\section{Background}

Patients with schizophrenia suffer from moderate to severe cognitive impairment especially in the domains of attention, executive functioning, memory, verbal skills, and processing speed impairments [1,2]. Cognitive deficits may represent a core pathophysiological feature of the illness, and these deficits have been found in first episode patients, as well as first-degree relatives of schizophrenia patients $[3,4]$.

\footnotetext{
* Correspondence: fengcsu@yahoo.com.cn

${ }^{1}$ Institute of Mental Health, the Second Xiangya Hospital, Central South University, No. 139 Renmin Mid Road, Changsha 410011, China

Full list of author information is available at the end of the article
}

Obesity is common in the schizophrenia population [5]. According to recent studies, $40-60 \%$ of schizophrenia patients are overweight or obese [6-10]. Accumulating evidence indicates that obesity is associated with cognitive dysfunction in non-schizophrenia populations [11-14]. A cross-sectional study of 2,223 healthy workers aged 32 to 62 years showed that body mass index (BMI) was independently associated with cognitive function (word-list learning and the Digit-symbol Substitution Test) [15]. Another study in patients with bipolar disorder suggested that overweight and obesity had a potential negative effect on cognitive function [16]. The cognitive domains most

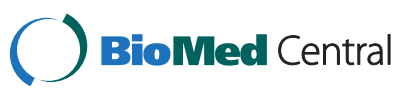

(c) 2013 Guo et al.; licensee BioMed Central Ltd. This is an Open Access article distributed under the terms of the Creative Commons Attribution License (http://creativecommons.org/licenses/by/2.0), which permits unrestricted use, distribution, and reproduction in any medium, provided the original work is properly cited. 
likely adversely affected by excess weight include learning, memory and executive function.

Previous studies in Asian populations have shown that Asians have higher amounts of body fat at lower BMIs than do Western populations, leading to a higher risk for poorer cognitive function in Asian people than in Western people with comparable BMIs [17]. Therefore, there might be differential relationships between obesity as measured by BMI and cognitive function across different racial or ethnic populations.

It has been well documented that overweight or obesity is associated with decreased self-esteem and quality of life, treatment noncompliance, and increased risk for medical comorbidity in schizophrenia [18-20]. However, few previous studies have specifically examined the relationship between overweight or obesity and cognitive function in this patient population. The purpose of this study was to investigate how obesity might be associated with cognitive function in Chinese patients with schizophrenia.

\section{Methods \\ Sample}

This study was part of the Early-stage Schizophrenia Outcome Study (ESOS), which involved 10 different sites across China [20]. Study participants were enrolled from psychiatric outpatient clinics. The inclusion criteria were: (1) age range between 18 to 50 years old; (2) diagnosis of schizophrenia or schizophreniform disorder as determined by the Structured Clinical Interview for DSM-IV Axis I Disorders-Clinician Version administered by study investigators or trained staff; (3) duration of illness $\leq 5$ years; (4) in stable clinical condition (the Positive and Negative Syndrome Scale [PANSS][21]total scores $\leq 60)$; (5) on only one oral antipsychotic agent. The exclusion criteria were: (1) a history of neurologic disorders that might affect cognitive function (i.e. head injury, cerebrovascular disease, Parkinson's disease, Alzheimer's disease, seizure disorder), (2) serious or unstable medical condition (i.e. poorly controlled diabetes or hypertension, symptomatic coronary artery disease) or BMI $\geq 45 \mathrm{~kg} / \mathrm{m}^{2}$; (3) current pregnancy or breastfeeding, or history of pregnancy in the past 12 months; (4) substance abuse or dependence in the past 3 months.

The study was performed in accordance with the Declaration of Helsinki and approved by the Institutional Review Board at the Second Xiangya Hospital, Chongqing Mental Health Center, Psychiatric Hospital of Jiangxi Province, West China Hospital, Mental Hospital of Henan Province, Beijing Anding Hospital, Shanghai Mental Health Center, Guangzhou Brain Hospital, Hunan Brain Hospital, and Nanjing Brain Hospital. A written informed consent was obtained from each subject, or his or her legal guardians.

\section{Cognitive assessment}

A cognitive battery was administered to all participants. The battery includes the following five cognitive tests:

1) the Wechsler Adult Intelligence Scale-Revised Digit Symbol Test [22]: this is a test of processing speed requiring the examinee to copy symbols that match the numbers 1 through 9 according to a key; the number of symbols completed correctly within 120 seconds was used as the performance measure.

2) Trail Making Test, Part A and B [23]: these tests measure processing speed and executive function, respectively. Part A requires the subject to draw lines connecting numbers in order; Part B requires the subject to alternate between numbers and letters. The time to complete each test was used as the performance measure.

3) The Wechsler Adult Intelligence Scale-Revised Digit Span Test [22]: this test measures attention and working memory and requires the subject to repeat increasingly long strings of digits forward, and then backward. The number of correctly recalled trials in each condition was used as the performance measure.

4) The computerized Wisconsin Card Sorting Test (WCST, 128-card version) [24]: this is a commonly used test for executive function, measuring abstraction and cognitive flexibility; the number of categories completed and the number of perseverative errors were used as the performance measures.

5) The Wechsler Memory Scale-Revised Visual Reproduction Test [25]: this is a visual learning and memory test requiring the subject to copy and recall abstract line drawings; the immediate recall raw score was used as the performance measure. The eight performance measures were grouped into 4 domains including Processing Speed (Digit Symbol; Trail Making Test, Part A), Attention/ Working Memory (Digit Span total), Executive Functioning (Trail Making Test, Part B; WCST perseverative errors and categories completed), and Visual Memory (Visual Reproduction). All the tests were administered by raters with a masters degree in clinical psychology; an inter-rater reliability was established. The raters were blind to participants' medical status at the time of assessment.

\section{Clinical and BMI measurements}

Clinical symptoms were assessed using the Positive and Negative Syndrome Scale (PANSS) [21] and the Montgomery and Asberg Depression Scale (MADRS) [26]. 
Height and weight were measured using the standardized procedures. BMI was calculated based on the formula: weight in kilograms divided by height in meters-squared $\left(\mathrm{kg} / \mathrm{m}^{2}\right)$. According to the World Health Organization Standard classification on body mass index for Asians [27], subjects were defined as underweight $\left(<18.5 \mathrm{~kg} / \mathrm{m}^{2}\right)$, normal weight $\left(18.5-22.9 \mathrm{~kg} / \mathrm{m}^{2}\right)$, overweight $\left(23-27.4 \mathrm{~kg} / \mathrm{m}^{2}\right)$ and obese $\left(\geq 27.5 \mathrm{~kg} / \mathrm{m}^{2}\right)$.

\section{Statistical analysis}

All analyses were conducted using the Statistical Package for Social Sciences, version 15.0 (SPSS Inc, Chicago, Illinois). A cognitive composite score was derived based on the scores on the five cognitive tests. Raw scores were first converted to standardized z-scores with the mean of 0 and the standard deviation of 1 . For domains with more than one test, a domain $\mathrm{z}$-score was created by calculating the mean of the z-scores for the measures comprising the domain, then converting the mean to a $\mathrm{z}$ score with a mean of zero and a standard deviation of 1. A cognitive composite score was calculated by creating a $\mathrm{z}$ score of the average of the 4 standardized domain scores.

Demographic and clinical characteristics across different BMI groups were compared using analysis of variance (ANOVA) for continuous variables and Chi-square tests for categorical variables. Group comparisons of cognitive function were performed using analysis of covariance (ANCOVA) controlling for gender. If an overall group difference was found to be significant, post hoc comparisons were then evaluated using the Hochberg modification of the Bonferroni correction for multiple comparisons: the adjusted alpha for statistical significance was calculated as $\alpha^{*}=\alpha /[\mathrm{k}(\mathrm{k}-1) / 2]=0.05 /\left[4^{*}(4-1) / 2\right]=0.008$ [28]. The

Table 1 Demographic and clinical characteristics of the study sample ${ }^{a}$

\begin{tabular}{|c|c|c|c|c|c|c|}
\hline Characteristic & $\begin{array}{l}\text { Underweight } \\
\quad(n=57)\end{array}$ & $\begin{array}{l}\text { Normal weight } \\
\quad(n=358)\end{array}$ & $\begin{array}{c}\text { Overweight } \\
(n=319)\end{array}$ & $\begin{array}{l}\text { Obese } \\
(n=162)\end{array}$ & $F / X^{2}$ & $p$ value \\
\hline Age (years) & $27.6 \pm 8.5$ & $27.1 \pm 7.6$ & $27.8 \pm 6.6$ & $27.8 \pm 7.6$ & 0.738 & 0.529 \\
\hline Male, N (\%) & $22(38.6)$ & $162(45.3)$ & $203(63.6)$ & $106(65.4)$ & 36.683 & $<0.001^{\mathrm{b}}$ \\
\hline Marital Status, N (\%) & & & & & 3.931 & 0.686 \\
\hline Married & $37(64.9)$ & 243(67.9) & 197(61.8) & 106(65.4) & & \\
\hline Never married & $16(28.1)$ & $94(26.3)$ & 103(32.3) & $49(30.2)$ & & \\
\hline Widowed, divorced, or separated & $4(7.0)$ & $21(5.9)$ & $19(6.0)$ & $7(4.3)$ & & \\
\hline Education (years) & $12.6 \pm 2.8$ & $12.5 \pm 3.0$ & $12.4 \pm 2.9$ & $12.9 \pm 2.8$ & 1.264 & 0.286 \\
\hline Occupation, N (\%) & & & & & 6.301 & 0.098 \\
\hline Office worker & $20(35.1)$ & 159(44.4) & 113(35.4) & $66(40.7)$ & & \\
\hline Manual worker & $37(64.9)$ & 199(55.6) & $206(64.6)$ & $96(59.3)$ & & \\
\hline Smoking cigarettes, N (\%) & $9(15.8)$ & $53(17.4)$ & $61(19.1)$ & $31(19.1)$ & 3.423 & 0.330 \\
\hline FBS (mg/dl) & $88.8 \pm 12.7$ & $89.1 \pm 12.0$ & $89.3 \pm 11.1$ & $92.0 \pm 18.8$ & 0.809 & 0.489 \\
\hline $\mathrm{SBP}(\mathrm{kPa})$ & $15.1 \pm 1.0$ & $14.9 \pm 1.2$ & $15.0 \pm 1.2$ & $15.2 \pm 1.2$ & 2.119 & 0.096 \\
\hline $\mathrm{DBP}(\mathrm{kPa})$ & $9.9 \pm 1.0$ & $9.8 \pm 0.8$ & $9.9 \pm 0.8$ & $10.0 \pm 0.8$ & 1.996 & 0.113 \\
\hline DSM-IV diagnosis, N (\%) & & & & & 2.251 & 0.522 \\
\hline Schizophrenia & $52(91.2)$ & $300(83.8)$ & $273(85.6)$ & 137(84.6) & & \\
\hline Schizophreniform disorder & $5(8.8)$ & $58(16.2)$ & $46(14.4)$ & $25(15.4)$ & & \\
\hline Duration of illness (years) & $2.2 \pm 1.8$ & $2.0 \pm 1.7$ & $2.1 \pm 1.8$ & $2.4 \pm 1.8$ & 1.706 & 0.164 \\
\hline PANSS total score & $47.6 \pm 16.5$ & $44.8 \pm 14.6$ & $44.8 \pm 14.6$ & $46.0 \pm 12.9$ & 1.325 & 0.265 \\
\hline MADRS total score & $5.0 \pm 5.5$ & $5.2 \pm 5.7$ & $5.1 \pm 5.5$ & $5.3 \pm 5.5$ & 0.106 & 0.956 \\
\hline Current medication, N (\%) & & & & & 7.063 & 0.070 \\
\hline Typical antipsychotics & 21(31.6) & 109(30.4) & $71(22.3)$ & $39(24.1)$ & & \\
\hline Atypical antipsychotics & $36(68.4)$ & $249(69.6)$ & 248(77.7) & 123(75.9) & & \\
\hline Mean daily doses of medication (clorpromazine quivalent, mg/d) & $315.7 \pm 107.3$ & $320.8 \pm 104.4$ & $322.0 \pm 113.0$ & $331.3 \pm 115.5$ & 0.447 & 0.719 \\
\hline Body mass index $\left(\mathrm{kg} / \mathrm{m}^{2}\right)$ & $16.5 \pm 2.4$ & $21.1 \pm 1.9$ & $24.9 \pm 1.3$ & $29.6 \pm 2.4$ & 2203.838 & $<0.001$ \\
\hline
\end{tabular}

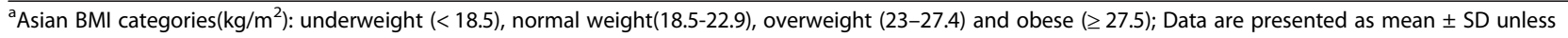
otherwise indicated. Percentages may not sum up to 100 because of rounding.

${ }^{b}$ underweight vs overweight, $p<0.001$; underweight vs obese, $p<0.001$; normal weight vs overweight, $p<0.001$; normal weight vs obese, $p<0.001$; Abbreviation: FBS, fasting blood glucose; SBP, systolic blood pressure; DBP, diastolic blood pressure; DSM-IV, Diagnostic and Statistical Manual of Mental Disorders Fourth Edition; PANSS, the Positive and Negative Syndrome Scale; MADRS, Montgomery-Asberg Depression Scale. 
Table 2 Partial correlations between body mass index and cognitive function measures controlling for both age and gender

\begin{tabular}{lcc}
\hline Characteristic & Body mass index & p value \\
\hline WAIS-R Digit Symbol & -0.076 & 0.023 \\
Trail Making Test A & 0.016 & 0.641 \\
Trail Making Test B & 0.023 & 0.493 \\
WCST Perseverative Errors & 0.005 & 0.877 \\
WCST Categories Completed & -0.027 & 0.420 \\
WAIS-R Digit Span & -0.031 & 0.362 \\
WMS-R Visual Reproduction & -0.131 & $<0.001$ \\
Composite z score & -0.082 & 0.018 \\
\hline
\end{tabular}

Abbreviation: WAIS, Wechsler Adult Intelligence Scale-Revised; WCST, Computerized Wisconsin Card Sorting Test; WMS-R, Wechsler Memory Scale-Revised; $B M I$, Body mass index.

correlations between BMI and cognitive function measures were performed using partial correlation tests controlling for both age and gender.

\section{Results}

\section{Characteristics of the sample}

A total of 896 patients completed the study and were included in the data analysis. The prevalence of obesity, overweight, and underweight were $18.1 \%, 35.6 \%$ and $6.4 \%$ respectively.

As shown in Table 1, there were no significant differences across different BMI groups (obesity, overweight, normal weight and underweight) on various demographic or clinical characteristics ( $p$ 's $>0.05$ ) except for gender $(\mathrm{p}<0.001)$.

\section{Correlations between BMI and cognitive measures}

Correlations between BMI and various cognitive measures are showed in Table 2. Partial correlation analysis adjusting for gender demonstrated that a higher BMI was significantly associated with lower scores on the WAIS-R
Digit Symbol test, the WMS-R Visual Reproduction test, and the composite $\mathrm{z}$ score (p's $\leq 0.024)$.

\section{Comparison of cognitive measures across different BMI groups}

There were significant overall group differences in the Trail Making Test B, the WMS-R Visual Reproduction test, the WAIS Digit Symbol test, and the composite $\mathrm{z}$ score (p's $\leq 0.040$; Table 3). Post hoc analysis revealed that the obese group had significantly lower scores on the Trail Making Test B, the WMS-R Visual Reproduction test, the WAIS Digit Symbol test, and the composite z score compared with the normal weight group (p's $\leq 0.004$ ).

\section{Gender, obesity, and cognitive measures}

There was a significant difference in BMI between males and females $(24.1 \pm 3.7$ and $22.8 \pm 3.1$, respectively, $\mathrm{F}=$ 29.872, $\mathrm{p}<0.001)$. However, there were no significant differences in various cognitive measures between the two gender groups (p's $>0.05$; data not shown). Further analysis within each gender group showed that the obese group had significantly lower scores on the WMS-R Visual Reproduction test, the WAIS Digit Symbol test, and the composite $\mathrm{z}$ score compared with the normal weight group (p's $\leq$ 0.004; data not shown).

\section{Antipsychotic agents, obesity and cognitive measures}

There was a significant difference in BMI between patients on typical antipsychotics and those on atypical antipsychotics $(22.9 \pm 3.5$ and $23.6 \pm 3.5$, respectively, $F=10.909$, $\mathrm{p}=0.001$ ), but there were no significant differences in various cognitive measures between those taking typical vs. atypical antipsychotics (p's $>0.05$; data not shown).

\section{Discussion}

In this study, the percentage of overweight or obese Chinese patients with schizophrenia was $54 \%$, which is higher than in the general Chinese population (43.1\%) [29].

Table 3 Comparisons of cognitive function measures across different BMI groups ${ }^{\mathrm{a}}$

\begin{tabular}{|c|c|c|c|c|c|c|}
\hline Characteristic & Underweight $(n=57)$ & Normal weight $(n=358)$ & Overweight $(n=319)$ & Obese $(n=162)$ & $F$ & $p$ value \\
\hline WAIS-R Digit Symbol & $47.5 \pm 15.8$ & $48.3 \pm 14.1$ & $46.6 \pm 12.8$ & $44.0 \pm 13.2$ & 3.922 & $0.009^{b}$ \\
\hline Trail Making Test A & $56.6 \pm 23.7$ & $52.5 \pm 24.3$ & $54.9 \pm 29.5$ & $55.6 \pm 27.3$ & 0.842 & 0.471 \\
\hline Trail Making Test B & $112.3 \pm 59.0$ & $106.7 \pm 54.6$ & $114.4 \pm 61.4$ & $123.7 \pm 55.5$ & 2.784 & $0.040^{c}$ \\
\hline WCST Perseverative Errors & $40.4 \pm 25.8$ & $42.7 \pm 24.7$ & $42.9 \pm 23.7$ & $41.6 \pm 26.5$ & 0.241 & 0.868 \\
\hline WCST Categories Completed & $2.7 \pm 2.2$ & $2.5 \pm 2.1$ & $2.6 \pm 2.1$ & $2.8 \pm 2.2$ & 0.491 & 0.688 \\
\hline WAIS-R Digit Span & $12.0 \pm 3.8$ & $12.5 \pm 3.5$ & $12.3 \pm 3.1$ & $11.9 \pm 3.0$ & 1.606 & 0.186 \\
\hline WMS-R Visual Reproduction & $8.9 \pm 2.8$ & $9.3 \pm 3.0$ & $8.6 \pm 2.9$ & $8.2 \pm 3.5$ & 5.921 & $0.001^{d}$ \\
\hline Composite z score & $0.10 \pm 0.09$ & $0.20 \pm 0.03$ & $0.10 \pm 0.03$ & $0.01 \pm 0.05$ & 4.365 & $0.005^{\mathrm{e}}$ \\
\hline
\end{tabular}

${ }^{a}$ Asian BMI categories $\left(\mathrm{kg} / \mathrm{m}^{2}\right)$ : underweight $(<18.5)$, normal weight(18.5-22.9), overweight (23-27.4) and obese ( $\left.\geq 27.5\right)$; Data are presented as mean \pm SD. ${ }^{b}$ normal weight vs obese, $P=0.001 ;{ }^{c}$ normal weight vs obese, $P=0.004 ;{ }^{d}$ normal weight vs obese, $P=0.001$; normal weight vs overweight, $P=0.012{ }^{e}$ normal weight vs obese, $\mathrm{P}=0.004$;

Abbreviation: WAIS, Wechsler Adult Intelligence Scale-Revised; WCST, Computerized Wisconsin Card Sorting Test; WMS-R, Wechsler Memory Scale-Revised; BMI, Body mass index. 
Moreover, we found that obese patients with schizophrenia demonstrated poorer cognitive performance than the normal weight patients. To our knowledge, this is the largest study to assess the relationship between obesity and cognitive function in schizophrenia. The findings of this study suggested that obesity, in addition to being a risk factor for various medical conditions, is associated with decreased cognitive function in patients with schizophrenia.

The exact mechanisms linking obesity and cognitive dysfunction remain unclear. Obesity is associated with vascular changes, impaired insulin regulation, and reduced cardiovascular fitness, which all might contribute to decreased cognitive function [30-32]. In addition, nonvascular mechanisms linking obesity with cognitive impairment have also been suggested [33]. Leptin, an adipocyte-secreted protein related to obesity, may play a role in learning and memory [34]. Interestingly, higher levels of serum leptin appear to protect against cognitive decline in elderly individuals, suggesting leptin resistance as a causal pathway from obesity to cognitive impairment [35]. It is also possible that schizophrenia patients with cognitive impairment are more likely to become obese [12]. If so, much additional work is needed to clarify the association between BMI and worse cognitive performance.

In our study, a higher BMI was found in patients treated with atypical antipsychotics than in those treated with typical agents. However, there was no significant difference in cognitive function between patients on typical vs. atypical antipsychotics. Some atypical antipsychotic agents are associated with significant metabolic side effects; typical antipsychotic agents are more likely to cause other side effects such as extrapyramidal symptoms [36]. This may be the reason why previous studies showed atypical antipsychotic agents are associated with better cognitive function than typical agents in patients with schizophrenia [37].

\section{Limitations}

There are several limitations to this study. First, a more comprehensive cognitive battery might have revealed different results. Second, the participants were not randomly selected and the study excluded patients with serious or unstable medical conditions; as a result, the study sample may not be representative of individuals with schizophrenia in China. Third, given the crosssectional study design, causal relationships cannot be drawn based on our findings. Fourth, BMI may not be the most appropriate measure to reflect obesity and its negative impact on cardiometabolic disorders and other health conditions [38]. Future studies using more sophisticated techniques, such as dual-energy X-ray absorptiometry, to measure body composition and percentage of fat are needed.

\section{Conclusion}

Our study suggests that, in addition to its well established risk for various cardiometabolic conditions, obesity is also associated with worse cognitive function in Chinese patients with schizophrenia. Future studies should explore if weight loss and management can improve cognitive function in obese patients who suffer from schizophrenia.

\section{Abbreviations}

BMI: Body mass index; WMS-R: The wechsler memory scale-revised; WAISR: The wechsler adult intelligence scale-revised; PANSS: Positive and negative syndrome scale; WCST: Wisconsin card sorting test; MADRS: Montgomery and asberg depression scale.

\section{Competing interests}

All authors declare that they have no competing interests.

\section{Authors' contributions}

GF carried out the study, participated in the analysis and interpretation of data and wrote the manuscript. ZC, WL, LL and WR were involved in carrying out the study and revising the manuscript. ZP conceived of the study and participated in its design and coordination and obtained the funding. All authors contributed to the article and approved the final manuscript.

\section{Acknowledgements}

We wish to thank all the investigators of Early-stage Schizophrenia Outcome Study (ESOS) who enrolled patients and collected data: Dr. B. Wang, Dr. B. Hu, Dr. X. Sun, Dr. L. Lv, Dr. C. Wang, Dr. Z. Lu, Dr. C. Ma, Dr. T. Guo, and Dr. S. Xie. We are also very grateful to X. Fan from Massachusetts General Hospital, Harvard Medical School and E. W. Twamley from Department of Psychiatry, University of California for assistance in revising our manuscript. This study was supported by the National Key Technologies R\&D Program in the 10th 5-year-plan of China (Grant No. 2004BA720A22); the National Natural Science Foundation of China (Grant No. 30900485 and 81270019); and the National R\&D Special Fund for Health Profession (Grant No. 201002003).

\section{Author details}

${ }^{1}$ Institute of Mental Health, the Second Xiangya Hospital, Central South University, No. 139 Renmin Mid Road, Changsha 410011, China. ${ }^{2}$ Department of Psychiatry, 3rd Affiliated Hospital of Sun Yat-sen University, Guangzhou, China.

Received: 24 November 2012 Accepted: 27 March 2013 Published: 9 April 2013

\section{References}

1. Green MF, Kern RS, Braff DL, Mintz J: Neurocognitive deficits and functional outcome in schizophrenia: are we measuring the "right stuff"? Schizophr Bull 2000, 26(1):119-136.

2. Goldberg TE, Goldman RS, Burdick KE, Malhotra AK, Lencz T, Patel RC, Woerner MG, Schooler NR, Kane JM, Robinson DG: Cognitive improvement after treatment with second-generation antipsychotic medications in first-episode schizophrenia: is it a practice effect? Arch Gen Psychiatry 2007, 64(10):1115-1122.

3. Hill SK, Schuepbach D, Herbener ES, Keshavan MS, Sweeney JA: Pretreatment and longitudinal studies of neuropsychological deficits in antipsychotic-naive patients with schizophrenia. Schizophr Res 2004, 68(1):49-63.

4. Snitz BE, Macdonald AR, Carter CS: Cognitive deficits in unaffected first-degree relatives of schizophrenia patients: a meta-analytic review of putative endophenotypes. Schizophr Bull 2006, 32(1):179-194.

5. Susce MT, Villanueva N, Diaz FJ, de Leon J: Obesity and associated complications in patients with severe mental illnesses: a cross-sectional survey. J Clin Psychiatry 2005, 66(2):167-173.

6. Coodin S: Body mass index in persons with schizophrenia. Can J Psychiatry 2001, 46(6):549-555.

7. Catapano L, Castle D: Obesity in schizophrenia: what can be done about it? Australas Psychiatry 2004, 12(1):23-25. 
8. Schwartz TL, Nihalani N, Jindal S, Virk S, Jones N: Psychiatric medicationinduced obesity: a review. Obes Rev 2004, 5(2):115-121.

9. Tardieu S, Micallef J, Gentile S, Blin O: Weight gain profiles of new antipsychotics: public health consequences. Obes Rev 2003, 4(3):129-138.

10. Muller DJ, Muglia P, Fortune T, Kennedy JL: Pharmacogenetics of antipsychotic-induced weight gain. Pharmacol Res 2004, 49(4):309-329.

11. Taki Y, Kinomura S, Sato K, Inoue K, Goto R, Okada K, Uchida S, Kawashima R, Fukuda $\mathrm{H}$ : Relationship between body mass index and gray matter volume in 1,428 healthy individuals. Obesity (Silver Spring) 2008, 16(1):119-124.

12. Gunstad J, Paul RH, Cohen RA, Tate DF, Spitznagel MB, Gordon E: Elevated body mass index is associated with executive dysfunction in otherwise healthy adults. Compr Psychiatry 2007, 48(1):57-61.

13. Gunstad J, Spitznagel MB, Paul RH, Cohen RA, Kohn M, Luyster FS, Clark R, Williams LM, Gordon E: Body mass index and neuropsychological function in healthy children and adolescents. Appetite 2008, 50(2-3):246-251.

14. Gunstad J, Lhotsky A, Wendell CR, Ferrucci L, Zonderman AB: Longitudinal examination of obesity and cognitive function: results from the Baltimore longitudinal study of aging. Neuroepidemiology 2010, 34(4):222-229.

15. Cournot M, Marquie JC, Ansiau D, Martinaud C, Fonds H, Ferrieres J, Ruidavets $\mathrm{JB}$ : Relation between body mass index and cognitive function in healthy middle-aged men and women. Neurology 2006, 67(7):1208-1214.

16. Yim CY, Soczynska JK, Kennedy SH, Woldeyohannes HO, Brietzke E, Mclntyre RS: The effect of overweight/obesity on cognitive function in euthymic individuals with bipolar disorder. Eur Psychiatry 2012, 27(3):223-228.

17. Fan X, Borba CP, Copeland P, Hayden D, Freudenreich O, Goff DC Henderson DC: Metabolic effects of adjunctive aripiprazole in clozapinetreated patients with schizophrenia. Acta Psychiatr Scand 2013, 127(3):217-226.

18. Lieberman JA, Stroup TS, McEvoy JP, Swartz MS, Rosenheck RA, Perkins DO, Keefe RS, Davis SM, Davis CE, Lebowitz BD, et al: Effectiveness of antipsychotic drugs in patients with chronic schizophrenia. N Engl J Med 2005, 353(12):1209-1223.

19. Saddichha S, Vishnuvardhan G, Akhtar S: Obesity, diabetes and hypertension associated with antipsychotic use in remitted schizophrenia. Int J Risk Saf Med 2011, 23(3):181-185.

20. Guo X, Zhai J, Liu Z, Fang M, Wang B, Wang C, Hu B, Sun X, Lv L, Lu Z, et al: Effect of antipsychotic medication alone vs combined with psychosocial intervention on outcomes of early-stage schizophrenia: A randomized, 1-year study. Arch Gen Psychiatry 2010, 67(9):895-904.

21. Kay SR, Fiszbein A, Opler LA: The positive and negative syndrome scale (PANSS) for schizophrenia. Schizophr Bull 1987, 13(2):261-276.

22. Wechsler D: The wechsler adult intelligence scale-revised. New York: Psychological Corp; 1981.

23. Reitan RM, Wolfson D: The halstead-reitan neuropsychological test battery: theory and clinical interpretation. 2nd edition. South Tucson, Ariz: Neuropsychology Press; 1993

24. Heaton RK, Chelune GJ, Talley JL, Kay GG, Curtis G: Wisconsin card sorting test manual. Odessa, Fla: Psychological Assessment Resources; 1993.

25. Wechsler D: The wechsler memory scale-revised. San Antonio, Tex Psychological Corp; 1987.

26. Davidson J, Turnbull CD, Strickland R, Miller R, Graves K: The montgomeryasberg depression scale: reliability and validity. Acta Psychiatr Scand 1986, 73(5):544-548

27. WHO Expert Consultation: Appropriate body-mass index for Asian populations and its implications for policy and intervention strategies. Lancet 2004, 363(9403):157-163.

28. Howell DC: Statistical methods for psychology. 7th edition. Australia, Wadsworth: Cengage Learning; 2009.

29. Wang $R$, Wu MJ, Ma XQ, Zhao YF, Yan XY, Gao QB, He J: Body mass index and health-related quality of life in adults: a population based study in five cities of China. Eur J Public Health 2012, 22(4):497-502.

30. Convit A, Wolf OT, Tarshish C, de Leon MJ: Reduced glucose tolerance is associated with poor memory performance and hippocampal atrophy among normal elderly. Proc Natl Acad Sci U S A 2003, 100(4):2019-2022.

31. Rahmouni K, Correia ML, Haynes WG, Mark AL: Obesity-associated hypertension: new insights into mechanisms. Hypertension 2005, 45(1):9-14.

32. Ylikoski R, Ylikoski A, Raininko R, Keskivaara P, Sulkava R, Tilvis $R$, Erkinjuntti $T$ : Cardiovascular diseases, health status, brain imaging findings and neuropsychological functioning in neurologically healthy elderly individuals. Arch Gerontol Geriatr 2000, 30(2):115-130.
33. Friedman Jl, Wallenstein S, Moshier E, Parrella M, White L, Bowler S, Gottlieb S, Harvey PD, McGinn TG, Flanagan L, et al: The effects of hypertension and body mass index on cognition in schizophrenia. Am J Psychiatry 2010, 167(10):1232-1239.

34. Funahashi $H$, Yada T, Suzuki R, Shioda S: Distribution, function, and properties of leptin receptors in the brain. Int Rev Cytol 2003, 224:1-27.

35. Holden KF, Lindquist K, Tylavsky FA, Rosano C, Harris TB, Yaffe K: Serum leptin level and cognition in the elderly: findings from the health $A B C$ study. Neurobiol Aging 2009, 30(9):1483-1489.

36. Leucht S, Corves C, Arbter D, Engel RR, Li C, Davis JM: Second-generation versus first-generation antipsychotic drugs for schizophrenia: a meta-analysis. Lancet 2009, 373(9657):31-41.

37. Hill SK, Bishop JR, Palumbo D, Sweeney JA: Effect of second-generation antipsychotics on cognition: current issues and future challenges. Expert Rev Neurother 2010, 10(1):43-57.

38. Romero-Corral A, Montori VM, Somers VK, Korinek J, Thomas RJ, Allison TG, Mookadam F, Lopez-Jimenez F: Association of bodyweight with total mortality and with cardiovascular events in coronary artery disease: a systematic review of cohort studies. Lancet 2006, 368(9536):666-678.

doi:10.1186/1471-244X-13-109

Cite this article as: Guo et al:: The relationship between obesity and neurocognitive function in Chinese patients with schizophrenia. BMC Psychiatry 2013 13:109.

\section{Submit your next manuscript to BioMed Central and take full advantage of:}

- Convenient online submission

- Thorough peer review

- No space constraints or color figure charges

- Immediate publication on acceptance

- Inclusion in PubMed, CAS, Scopus and Google Scholar

- Research which is freely available for redistribution

Submit your manuscript at www.biomedcentral.com/submit
C) Biomed Central 